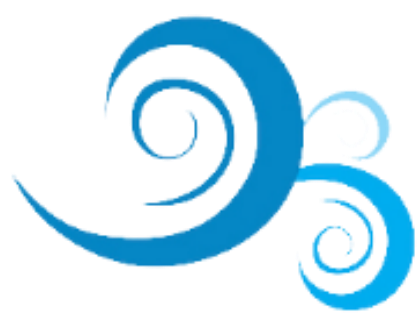

\title{
ESPAÇO SOCIAL E SIMBÓLICO DO NEGRO NA PRODUÇÃO ACADÊMICA BRASILEIRA DAS RELAÇÕES INTERNACIONAIS NO SÉCULO XXI
}

\author{
BLENDA SANTOS DE JESUS \\ Mestranda no Programa de Pós-Graduação em Relações Internacionais (PPGRI) pela \\ Universidade Federal da Bahia (UFBA). E-mail: contato.blenda@gmail.com
}

\begin{abstract}
RESUMO: O Brasil foi o último país das Américas a abolir o comércio transatlântico de pessoas, e, ainda hoje 0 afrodescendente sofre com a marginalização de sua figura, em razão do embranquecimento da sua identidade e conhecimento. Essa prática, conhecida como colonialismo epistemológico, atinge principalmente, mas não exclusivamente, a produção acadêmica das Relações Internacionais $(\mathrm{RI})$. Nesse contexto, o presente artigo objetiva analisar a representação das relações raciais na produção acadêmica brasileira das Relações Internacionais no século XXI. Para isso, investigamos quais vozes são predominantes nas $\mathrm{RI}$ e por quê, seguida de uma contextualização do negro na construção do discurso social e simbólico brasileiro, e a identificação de sua figura na produção acadêmica brasileira das RI. Utilizou-se abordagem metodológica de natureza qualitativa e quantitativa, com método de investigação dialético. Quanto aos procedimentos metodológicos, foi realizada revisão de literatura nacional e internacional e levantamento da produção acadêmica nacional stricto sensu.
\end{abstract}

PALAVRAS-CHAVE: negro; colonialismo epistemológico; Relações Internacionais.

\section{SOCIAL AND SYMBOLIC SPACE OF BLACK IN BRAZILIAN ACADEMIC PRODUCTION OF INTERNATIONAL RELATIONS IN THE 21st CENTURY}

\begin{abstract}
Brazil was the last country in the Americas to abolish transatlantic trade of people, and even today the African descendant suffers from the marginalization of his figure, due to the whitening of his identity and knowledge. This practice, known as epistemological colonialism, affects mainly, but not exclusively, the academic production of International Relations (IR). In this context, this article aims to analyze the representation of racial relations in the Brazilian academic production of International Relations in the 21st century. For this, we investigated which voices are predominant in IR and why, followed by a contextualization of black people in the construction of the Brazilian social and symbolic discourse, and the identification of its figure in the Brazilian academic production of IR. A qualitative and quantitative methodological approach was used with a dialectical research method. Regarding the methodological procedures, it was made a review of national and international literature and a research of the national academic production stricto sensu.
\end{abstract}

KEYWORDS: black; epistemological colonialism; International Relations 


\section{Introdução}

O que favorece a hegemonia das branquitudes acadêmicas é a política de citação.

Carla Akotirene Santos

Acredita-se que a primeira cátedra de Relações Internacionais (RI) foi fundada em 1919, em Aberystwyth, no Reino Unido (ROSENBERG, 2016). Apesar de não haver um entendimento entre os autores sobre a veracidade dessa informação, a disciplina tem obtido cada vez mais relevância acadêmica por sua abordagem interdisciplinar, que envolve questões como identidade, desigualdade, interseccionalidade, feminismo e antropoceno. $O$ interesse por assuntos internacionais interdisciplinares, em um mundo em exponencial complexidade, tem feito com que a oferta de cursos universitários no campo das RI aumente significativamente.

De acordo com o Instituto de Pesquisa de Relações Internacionais (IPRI), desde a implementação do primeiro curso de graduação em RI no Brasil - na Universidade de Brasília (UnB), em 1974 -, já foram criados mais 32 cursos em universidades públicas e 101 em universidades privadas, totalizando 134 cursos de graduação. Já os programas de pós-graduação, lato sensu e stricto sensu, contabilizam 30 cursos (IPRI, 2019). Esses são dados muito expressivos para uma disciplina relativamente recente, mas, apesar da sua aparente democratização, as RI ainda têm apresentado resistência na introdução e análise do conhecimento produzido fora do circuito ocidental.

"The problems lie in the way we think and are trained; in the subjects and approaches our discipline values and rewards"1 (BURKE et al., 2016, p. 3-4). Façamos um jogo: enumerar referências intelectuais que influenciam a produção acadêmica brasileira das RI. Quantas referências são europeias ou estadunidenses, quantas são brancas, negras e mulheres, e quantas são mulheres negras e homens negros. Aquele ou aquela que enumerar a maior quantidade de referências negras e afro-brasileiras é o(a) vencedor(a). Quantos pontos você obteve? Por considerar imprescindível a referência a autoras e autores negros, o presente artigo se

\footnotetext{
1 "Os problemas estão na maneira como pensamos e somos treinados; nos assuntos e abordagens que nossa disciplina valoriza e recompensa" Tradução livre.
} 
preocupa em citá-los majoritariamente. A escolha por essas referências também se deu pelo fato de serem negros e negras, mas foi muito mais influenciada pela qualidade de suas contribuições para os estudos sobre raça nas Relações Internacionais, e pela ausência da presença desses autores nos currículos acadêmicos das RI.

Pensadores africanos e afrodescendentes sofreram um apagamento no campo das RI ao longo da História, justificado pela concepção ocidental de que nenhum deles contribuiu significativamente para a disciplina (VITALIS, 2015). Essa concepção foi, majoritariamente, influenciada por pesquisas e publicações eugenistas, difundidas durante séculos em todo o mundo. Especialmente no Brasil, o último país das Américas a abolir o comércio transatlântico de pessoas (HERNÁNDEZ, 2017), políticas raciais marginalizaram as contribuições de representações negras. Mas, afinal, o que significa contribuir significativamente para o campo das RI? E, por que nenhum pensador negro foi capaz de fazê-lo?

A ausência de corpos negros nas universidades é uma das causas, mas, para além disso, há uma questão mais profunda e problemática, que envolve o uso da linguagem e do discurso social e simbólico como método de construção das ciências, e, consequentemente, das Relações Internacionais: o colonialismo epistemológico (FANON, 2008). Isto é, a institucionalização das RI como disciplina acadêmica de saberes ocidentais, brancos e heteronormativos.

Dessa forma, nossa compreensão sobre as Relações Internacionais foi influenciada por pensadores ocidentais clássicos que, como veremos, baseados em suas próprias observações, formularam conhecimentos e teorias colonialistas de subjugação das questões identitárias. Contudo, com o passar do tempo, as experiências e observações de estudiosos não-ocidentais sobre para que, e para quem, servem as RI, levou à revisão das teorias clássicas das Relações Internacionais, e como elas vieram a dominar.

O presente artigo objetiva, portanto, analisar a representação social e simbólica do negro na produção acadêmica brasileira das Relações Internacionais no século XXI. Para isso, utilizou-se abordagem metodológica de natureza qualitativa e quantitativa, com método de investigação dialético. A dialética pressupõe 0 intercâmbio de ideias, e, finalmente, o debate e a compreensão. "Compreender é exercer a capacidade de colocar-se no lugar do outro, tendo em 
vista que, como seres humanos, temos condições de exercitar esse entendimento" (MINAYO, 2012, p. 623). Quanto aos procedimentos metodológicos, foi realizada revisão de literatura nacional e internacional e levantamento da produção acadêmica nacional stricto sensu.

\section{Quem detém o conhecimento nas Relações Internacionais?}

Nas primeiras décadas do século $X X$, compreender as relações internacionais, a partir das Américas, também significava compreender as relações de raça (VITALIS, 2015). No entanto, no último século, essas relações têm se revelado um projeto do colonialismo ocidental, que se iniciou nos séculos XVI e XVII, em razão da chegada dos europeus ao "Novo Mundo" - como ficou conhecida, inicialmente, a região onde hoje se localizam as Américas do Norte e do Sul -. Segundo Inayatullah e Blaney (2004), esse projeto colonialista foi responsável por reforçar a interpretação do Outro como uma ameaça à estabilidade, à segurança e à ordem estabelecida pelos colonos europeus.

O Outro, como descrito por Santos (2002), é aquele que não está inserido no sistema dominante, e, devido à sua condição de outsider, seja ele empresa, instituição ou indivíduo, representa um obstáculo à realização plena dos direitos daqueles que representam o universal, isto é, o "não-Outro". Nessa estrutura, o Outro, no colonialismo ocidental, se torna “(...) a screen of projection for what the white subject fears to acknowledge about her/himself"2 (KILOMBA, 2010, p. 18).

Esse medo é responsável por criar um acordo tácito pelo qual a sociedade entende que o melhor é não falar sobre raça e racismo e sempre encarar as desigualdades raciais como um problema do Outro. "Assim, o medo e a projeção podem estar na gênese de processos de estigmatização de grupos que visam legitimar a perpetuação das desigualdades, a elaboração de políticas institucionais de exclusão e até de genocídio" (BENTO, 2002, p. 34). Cria-se uma perversidade sistêmica, que coisifica, vulnerabiliza e invisibiliza a identidade do Outro, e que é

\footnotetext{
2 "(...) uma tela de projeção para o que o sujeito branco tem medo de reconhecer sobre si mesmo" Tradução livre.
} 
responsável por instituir uma dinâmica racial pela qual raça e racismo são determinantes nos estudos das RI (PERSAUD, 2016).

Racismo é mais do que a intolerância contra o Outro. É a crença, as práticas e políticas de dominação estruturadas e institucionalizadas a partir do conceito de raça. Assim foram construídas as relações domésticas e internacionais dos principais Estados ocidentais; sob políticas de dominação racial, simbolizadas pela conquista territorial, pela escravização, pela colonização e pelo genocídio (HENDERSON, 2015). Aqui se inserem os povos das Américas e do Sul Global ${ }^{3}$. Nesse momento, entretanto, nos interessa analisar as relações de dominação que subjugaram africanos e afrodescendentes.

Em 1570, a população negra no Brasil era de aproximadamente 2000 a 3000 pessoas. A maioria das pessoas em situação de escravização nessa época ainda era majoritariamente de povos originários. Mas uma combinação de fatores que incluía, entre outras coisas, a resistência e o conhecimento avançado do território brasileiro em relação aos colonos Portugueses, o adoecimento e as mortes em massa dos povos originários, e, consequentemente, o declínio da produtividade comercial, fez com que esse quadro começasse a mudar. Dessa forma, entre $1576 \mathrm{e}$ 1591, mais de 40.000 africanos foram enviados ao Brasil para substituir os indígenas como mão de obra escravizada (THOMAS, 2006).

Àquela época, Portugal tornou-se um dos maiores comerciantes de pessoas do mundo, tornando o Brasil um de seus maiores receptores. Mesmo após a assinatura de documentos internacionais que proibiam o comércio transatlântico de pessoas, em 1826 e 1831, o Brasil manteve esse status. Estima-se que 45.000 africanos foram trazidos ilegalmente ao país, anualmente, nesse período. Segundo Thomas (2006, p. 628-629),

(...) Brazil, with her long history of reliance on slaves from Africa stretching back to the mid-sixteenth century, should take pride of place. For two years after 1831, when the slave trade had formally been abolished, few Africans were brought in because of the earlier heavy import when planters thought that slavery would soon end for ever. But then in the mid-1830s the trade recovered and was reorganized, on an

\footnotetext{
${ }^{3} \mathrm{O}$ termo Sul Global é frequentemente utilizado por instituições internacionais, como o Banco Mundial, para se referir aos países de baixa e média renda localizados em África, América Latina e Caribe, e Ásia. Isto é, os países localizados ao sul do globo terrestre, e que, historicamente, sofreram um atraso no processo de desenvolvimento.
} 
illegal basis, to serve plantations of cotton, though they were stagnating; of sugar, especially in new plantations near São Paulo and Campos; and, increasingly, of coffee in Rio, Minas Gerais, São Paulo and, above all, in the valley of the River Paraíba ${ }^{4}$

Mesmo após a assinatura da Lei Áurea, documento que aboliu formalmente a escravidão no Brasil, em 1888, africanos e afrodescendentes foram mantidos em condições sociais precárias e violentas. Ainda assim, o Estado brasileiro adotou o discurso de que após a abolição da escravatura, por ser um país diverso étnico e racialmente, o racismo era irrelevante ou inexistente e todos os povos viviam em harmonia. Essa ideia foi especialmente difundida no século $X X$, a partir do conceito de democracia racial, associado a autores como o sociólogo brasileiro Gilberto Freyre.

Diferente de outros países (como Estados Unidos e África do Sul), onde a colonização, escravização e segregação entre raças ocorreu de forma legalizada, no Brasil, de acordo com os defensores da democracia racial, a miscigenação racial fruto das relações entre índios, brancos e negros - foi responsável por formar uma sociedade evoluída, sem conflitos, ou seja, harmônica. Essa ideia logo se tornou o slogan do Estado brasileiro e foi utilizado amplamente com o objetivo de mitigar os conflitos de classes e desarticular os movimentos sociais por melhores condições para a população negra (BRAGA E MILANI, 2019; NASCIMENTO, 1984).

Não demorou muito para que o conceito de democracia racial fosse considerado desastroso por diversos pensadores e movimentos sociais brasileiros e sofresse duras críticas, sendo, inclusive, denominado de mito. Para Nascimento (1984, p. 18), "usou-se a falsa ciência social, a falsa ciência humana, manejando-se esse tipo de justificativa científica, que tem em Gilberto Freire o expoente máximo", a fim de beneficiar uma elite brasileira branca que detinha os poderes institucionais (políticos e jurídicos), e que, com a abolição da escravatura, não tinha a intenção de ceder direitos e espaços na sociedade.

\footnotetext{
4 "O Brasil, com sua longa história de dependência de escravos da África desde meados do século $\mathrm{XVI}$, deveria ter um lugar de destaque. Por dois anos depois de 1831, quando o comércio de escravos foi formalmente abolido, poucos africanos foram trazidos por causa da importação pesada anterior, quando os plantadores pensaram que a escravidão logo terminaria para sempre. Mas então, em meados da década de 1830, o comércio se recuperou e foi reorganizado, ilegalmente, para servir plantações de algodão, embora estivessem estagnadas; de açúcar, especialmente em novas plantações perto de São Paulo e Campos; e, cada vez mais, de café no Rio, Minas Gerais, São Paulo e, sobretudo, no vale do rio Paraíba." Tradução livre.
} 
Na prática, entretanto, o conceito de democracia racial continuou a orientar as políticas governamentais, influenciando o que Hernández (2017) denomina de "direito costumeiro de regulação racial" ou "a versão brasileira da legislação Jim Crow". Isto porque, o desejo de "purificar" a sociedade racialmente levou ao incentivo e à facilitação da entrada de imigrantes europeus e asiáticos no país a fim de substituir a mão de obra predominantemente africana e afrodescendente e evitar que essa população se inserisse na sociedade, adquirindo terras e trabalho.

Nesse sentido, leis foram aprovadas impossibilitando quaisquer direitos à essa população, proibindo, inclusive, o direito à propriedade para quilombolas e a proibição da imigração ou turismo de pessoas de ascendência africana no Brasil. Por outro lado, o Estado brasileiro investiu fortemente na imigração europeia e asiática, custeando passagens e oferecendo concessões de terras para aqueles que se estabelecessem no país (HERNÁNDEZ, 2017).

Com uma política de imigração explicitamente baseada em raça, legisladores brasileiros e atores da elite manifestaram expressamente 0 desejo de usar a imigração para erradicar os negros. (...) Em 1912, um intelectual da elite, João Batista Lacerda, que estava presente no primeiro Congresso Universal das Raças, de 1911, previu que, em 2012 , a população brasileira seria composta por $80 \%$ de brancos, $3 \%$ de mestiços e 17\% de indígenas; não haveria negros (HERNÁNDEZ, 2017, p. 57).

Apesar dos esforços empregados pelo Estado, a previsão não se cumpriu. De acordo com a Organização das Nações Unidas (ONU, 2016, p. 8), apenas nas Américas vivem, atualmente, cerca de 200 milhões de afrodescendentes. Ainda assim, esta é uma das populações mais marginalizadas em todo o mundo, acometida por altos índices de mortalidade e violência policial, além de acesso limitado à educação, saúde e justiça.

Diante desse cenário, em 23 de dezembro de 2013, a Assembleia Geral da Organização das Nações Unidas (ONU) adotou a Resolução 68/237 que proclama 2015 a 2024 como a Década Internacional de Afrodescendentes. Esta "(...) é uma ocasião para promover maior conhecimento, valor e respeito às conquistas da

\footnotetext{
${ }^{5}$ Leis de segregação racial aplicadas no Sul dos Estados Unidos entre os séculos XIX e XX, que, baseadas em teorias eugenistas, proibiam o contato e a interação entre brancos e negros.
} 
população afrodescendente e às suas contribuições para a humanidade" (ONU, 2016, p. 7).

As vulnerabilidades enfrentadas pela população afrodescendente, ainda hoje, são parte do legado da escravidão e do colonialismo, que estabeleceu a população branca ocidental como aquela destinada a construir e implementar a "civilização" em todos os espaços considerados bárbaros, selvagens e biologicamente inferiores (HENDERSON, 2015). Para Inayatullah e Blaney (2004), o Outro africano e afrodescendente, nesse sentido, representava uma ameaça às fontes clássicas de conhecimento europeias, em razão de sua vasta diversidade de cultos e culturas.

Essa diversidade exigiu dos europeus uma resposta intelectual que envolvia traduzir o Outro no tempo e espaço, isto é, categorizar o Outro em distintos degraus de humanidade e desenvolvimento (BLANEY E TICKNER, 2017). Aquele que assimilasse, e se assemelhasse, às narrativas ocidentais de linguagem, comportamento e religiosidade, tinha mais chances de evoluir cultural e espiritualmente, e, consequentemente, tornar-se menos desumano e subdesenvolvido. Afastar-se da "barbárie, selvageria e inferioridade", a exemplo dos dialetos e manifestações locais era imprescindível, de acordo com os colonos, no processo de "humanização" dos povos não-ocidentais e, portanto, dos povos de ascendência africana.

Nas Américas os africanos eram proibidos de pensar, rezar ou de praticar suas cosmologias, conhecimentos e visão de mundo. Estavam submetidos e um regime de racismo epistêmico que proibia a produção autônoma de conhecimento. A inferioridade epistêmica foi um argumento crucial, utilizado para proclamar uma inferioridade social biológica, abaixo da linha da humanidade. A ideia racista preponderante no século XVI era a de "falta de inteligência" dos negros, expressa no século XX como "os negros apresentam o mais baixo coeficiente de inteligência" (GROSFOGUEL, 2016, p. 40).

Esse jogo de dominação foi responsável por um processo contínuo e inacabado de embranquecimento do conhecimento africano e afrodescendente, denominado por Fanon (2008) como colonialismo epistemológico. Isto é, para além da subordinação material, política e geográfica, a colonização também promoveu uma subordinação epistemológica, intelectual, referente à produção de conhecimento. Nesse sentido, segundo Fanon (2008), os métodos pelos quais os 
conhecimentos científicos foram construídos estão arraigados por práticas coloniais de subjugação do Outro. Consistem, portanto, num projeto histórico de embranquecimento das ciências.

O branqueamento, ou embranquecimento,

[...] é um conceito de um significado individualizável, pessoal, e outro nacional, mais amplo. No nível individual, o branqueamento gira em torno do desejo de uma aparência branca e a ambição de ter filhos mais claros por meio de relações inter-raciais. (...) No nível nacional, o branqueamento é um conceito que descreve não só uma campanha concreta, de construção nacional e patrocinada pelo Estado para branquear a população, mas também a ideologia racial geral que valoriza a branquitude (HERNÁNDEZ, 2017, p. 32).

Em entrevista ao jornal EL PAÍS, o historiador, sociólogo e especialista no tema Lourenço Cardoso (2019) descreveu a branquitude como a pertença étnicoracial atribuída ao branco, que classifica o Outro em não-branco, o inferiorizando e transformando em um Não-Ser. A valorização da branquitude compreende, portanto, a etnicidade racial branca como a mais elevada hierarquicamente. O sujeito branco não é visto como um sujeito racializado, mas, simplesmente, como sujeito. Sua condição é humana e universal por si só. "Enquanto o negro (...) possui como parâmetro o branco, o branco não possui parâmetro porque ele é sua própria medida, seu próprio parâmetro" (CARDOSO, 2019, p.1).

Nesse contexto, enquanto a mulher e o homem negros precisam se afirmar enquanto negros e enquanto a mulher branca precisa se afirmar enquanto mulher, o homem branco é apenas um indivíduo e não precisa afirmar ou defender sua condição de pessoa (KILOMBA, 2010). De acordo com Nascimento (1984, p. 20), "até hoje, o negro ainda tem que pedir licença para dizer que é negro, para não ofender aos brancos", além disso, cabe ao negro o papel de identificar e comprovar o racismo presente na sociedade.

"No Brasil, o branqueamento é frequentemente considerado como um problema do negro que, descontente e desconfortável com sua condição de negro, procura identificar-se com o branco" (BENTO, 2002, p. 25) na tentativa de diluir suas características físicas. Pouco se questiona, contudo, sobre o processo que levou o branco a se tornar o modelo universal de humanidade, beleza e sabedoria, 
tampouco a projeção do branco sobre o negro e o estabelecimento do colonialismo epistemológico.

A linguagem, nesse sentido, opera como um sistema de representação (HALL, 1997) e possui importância fundamental para a difusão do colonialismo epistemológico, "uma vez que falar é existir absolutamente para o outro (...) é sobretudo assumir uma cultura, suportar o peso de uma civilização" (FANON, 2008, p. 33). Dessa forma, a linguagem, que simboliza a capacidade de se expressar, se torna um importante objeto de opressão no período colonial. Objeto esse que os colonizadores não só queriam como precisavam controlar a fim de que seu projeto de colonização fosse bem-sucedido (KILOMBA, 2010).

Para Fanon (2008), todo povo cuja colonização se deu por meio da destruição de sua cultura, assimila a linguagem da civilização colonizadora, na tentativa de escapar de sua própria barbárie, selvageria e inferioridade. A título de exemplo, um europeu que não comunica bem os saberes não-ocidentais é digno de empatia, pois possui linguagem, cultura e civilização próprias. Isto é, está inserido em determinado contexto de produção de conhecimento e identidade. Mas um africano ou afrodescendente que questiona a marginalização de sua civilização e da sua produção de conhecimento é considerado uma ameaça à harmonia do espaço em que está inserido.

Dessa forma, durante muitos séculos, "gestores escolares e professores receberam formação em teorias culturais e comportamentais que explicavam as fraquezas raciais e as políticas eugenistas que as corrigiriam" (HERNÁNDEZ, 2017, p. 64). Nesse contexto, a produção de conhecimento científico assimilou as narrativas ocidentais das civilizações colonizadoras e se encarregou de invisibilizar as demais narrativas não-ocidentais.

Como resultado, nosso trabalho na universidade ocidentalizada é basicamente reduzido a aprender essas teorias oriundas da experiência e dos problemas de uma região particular do mundo, com suas dimensões espaciais/temporais muito particulares e "aplicá-las" em outras localizações geográficas, mesmo que as experiências espaciais/temporais destas sejam completamente diferentes daquelas citadas anteriormente (GROSFOGUEL, 2016, p. 27).

Assim, disciplinas as mais variadas, das ciências naturais às sociais, sofreram um projeto histórico e contínuo de embranquecimento curricular. Nesse sentido, para 
Cardoso (2019), além de ser classificado como o Outro, o Não-Ser, e de ser coisificado e transformado em objeto de estudo científico - enquanto ao branco coube o papel de ser o pesquisador -, o negro também precisa lutar constantemente contra o silenciamento imposto à sua produção científica.

Por exemplo, os pesquisadores negros e negras são aqueles que possuem, a partir dos anos 1990, uma produção quantitativa e qualitativa melhor para tratar da questão racial. No entanto, os meios de comunicação acabam por optar em convidar o branco tanto para falar de negritude quanto de branquitude. Isto colabora para invisibilização da produção científica negra. O irônico é que muitos pesquisadores brancos aprenderam sobre os temas de raça, negritude e África, em geral, a partir das pesquisas dos seus orientandos negros e negras (CARDOSO, 2019, p.1).

Não é de se espantar, portanto, se a resposta à pergunta feita na introdução deste trabalho, sobre referências negras e afro-brasileiras que influenciam a produção acadêmica das Relações Internacionais, não tenha sido exitosa. Afinal, a política de citação acadêmica, isto é, a política de valorização da produção de conhecimento, é orientada pelo colonialismo epistemológico e beneficiada pela branquitude.

Um dos exemplos mais evidentes do colonialismo epistemológico nas Relações Internacionais se observa em uma de suas obras mais aclamadas; $A$ Política Entre As Nações, de Hans Morgenthau, publicada em 1948. Morgenthau, um dos mais influentes autores das RI, referia-se à África como um espaço politicamente vazio, reforçando a ideia de que apenas algumas nações - as mais ricas e, consequentemente, mais brancas - são capazes de contribuir significativamente para a produção de teorias das Relações Internacionais (HENDERSON, 2015).

Essa convicção propagou-se com sucesso nas universidades e centros de pesquisa no último século. Estudos sobre raça e colonialidade, e a contribuição de autores africanos e afrodescendentes, não compunham as ementas de cursos introdutórios às Relações Internacionais. Além disso, esses cursos não só eram destinados ao estudo das teorias ocidentais clássicas das RI (realistas, liberais e construtivistas), como eram frequentados por estudantes e professores majoritariamente brancos (VITALIS, 2015). 
Mesmo os pesquisadores que obtinham graus de Pós-Doutorado, nas mais prestigiadas universidades do mundo, precisavam criar suas próprias revistas e associações para abordar questões raciais nas RI. "Virtually every history of international relations to date turns out to be about white political scientists teaching in white departments and publishing in white journals"6 (VITALIS, 2015, p. 13).

A própria Foreign Affairs, uma das mais antigas e populares revistas acadêmicas sobre Relações Internacionais foi fundada com base em estudos sobre raça. A revista, fundada em 1910, com o título de Journal of Race Development, foi a primeira das Américas e tinha como objetivo discutir as questões raciais que influenciavam os padrões de civilização dos Estados. Porém, nove anos após a sua criação, a revista se torna Journal of International Relations e, posteriormente, em 1922 - quando passa a integrar uma organização estadunidense de relações exteriores -, Foreign Affairs (HENDERSON, 2015). Com essas mudanças, a revista perde seu objetivo originário e adquire um compromisso mais amplo com as relações internacionais.

Mas, afinal, para que - e para quem - servem as Relações Internacionais? As atuais configurações de mundo, que envolvem catástrofes ambientais e embates identitários aprofundados, nos leva a pensar que é o momento de as RI assumirem debates ainda mais diversificados, possibilitando a coexistência de corpos e territórios os mais variados. Isto pressupõe cultivar práticas anticoloniais, póscoloniais, ou decoloniais aperfeiçoadas, com características transdisciplinares e interseccionais (BLANEY e TICKNER, 2017).

"In IR, as elsewhere, a successful blending of culture and science requires a clear understanding of the historical context and the scholarly practices that have rendered them incompatible in the first place"7 (LAPID, 1996, p. 9). Por isso, nas últimas décadas, estudiosos iniciaram um movimento que busca reinventar criticamente a tradição acadêmica ocidental, a fim de criar e compartilhar saberes anticoloniais e não-ocidentais, aos quais referências africanas e afrodescendentes como W.E.B. Du Bois, Kwame Nkrumah, Frantz Fanon, Abdias do Nascimento, Lélia

\footnotetext{
6 "Praticamente toda a história das relações internacionais até hoje consiste em cientistas políticos brancos ensinando em departamentos brancos e publicando em revistas acadêmicas brancas" Tradução livre.

7 "Nas RI, assim como em outros lugares, uma combinação bem-sucedida de cultura e ciência requer uma clara compreensão do contexto histórico e das práticas acadêmicas que as tornaram incompatíveis em primeiro lugar" Tradução livre.
} 
Gonzalez, entre outros, ganham papel de destaque (SHILLIAM, 2011; PERSAUD e SAJED, 2018).

Esses estudiosos, segundo Henderson (2015), questionam a cumplicidade das principais categorias e recursos teóricos das Relações Internacionais em suposições raciais e coloniais que examinam práticas de racialização e construção da identidade racial. Diante do exposto, e inspirados por esse movimento, é que nos propomos a analisar a representação das relações raciais na produção acadêmica brasileira de Relações Internacionais no século XXI.

\section{O negro na produção acadêmica brasileira das Relações Internacionais}

"Cor negra. Que recebe a luz e não a reflete. Preto, escuro. Sombrio. Triste. Infeliz, mofino. Fúnebre, tétrico. Diz-se de ou indivíduo de pele muito escura. Diz-se de ou escravo de pele escura". Aqui, mais uma vez, é possível observar a utilização da linguagem como uma ferramenta extraordinária de identificação e cultura. Dessa vez, a partir da definição da palavra "negro" no Dicionário Aurélio da Língua Portuguesa, um dos mais vendidos do Brasil.

Como podemos notar, o uso do termo "negro" carrega uma herança fortemente associada a características que contém ou exprimem efeitos prejudiciais, maléficos e sub-humanos. A partir dos anos 1970, todavia, sua conotação historicamente pejorativa passa a ser ressignificada a partir da promoção de ações combativas e educativas do Movimento Negro Unificado (MNU), resultando em mudanças significativas no processo de construção da identidade de pessoas de ascendência africana no Brasil (PETRUCCELLI, 2013).

Conforme Petruccelli (2013), em 1976 a categoria de identificação "negro" nem sequer constava na lista das respostas espontâneas da Pesquisa Nacional por Amostra de Domícilios (PNAD), realizada pelo Instituto Brasileiro de Geografia e Estatística (IBGE). Atualmente, o IBGE classifica a população em cinco categorias; branca, preta, parda, amarela e indígena, sendo que, de 2012 a 2018, o número de pessoas que se autodeclararam negras (pretas e pardas) aumentou em 11,8 milhões. Dos mais de 210 milhões de brasileiros, portanto, cerca de 19,2 milhões se consideram pretos e 96,7 milhões, pardos. É evidente o aumento da representação 
negra nos dados que analisam a sociedade brasileira e por essa razão adotamos 0 termo "negro" para conduzir a análise da presente pesquisa.

A representação social é imprescindível para a transmissão de teorias e fenômenos que o indivíduo, por si só, não seria capaz de transmitir. Contudo, para Silva (2011, p. 28), “(...) a representação de uma realidade ou objeto não corresponde à sua percepção real, uma vez que esta tem o papel ativo de modelar o que apreende do exterior e reproduzir esta realidade ou objeto, reconstruindo-o". Nesse sentido, ainda que o percentual de auto identificação negra tenha aumentado nos últimos anos, a representação do negro nos espaços acadêmicos se manteve muito inferior à da população branca.

Segundo o IBGE (2019, p. 3), aproximadamente 4\% da população branca brasileira é analfabeta, enquanto esse número aumenta para 9,1\% ao se tratar da população negra. Quando falamos dos escolarizados, a disparidade se mantém. $55,8 \%$ das pessoas brancas concluíram o ensino básico obrigatório, contra 40,3\% dos negros. Já entre aqueles, de 15 a 29 anos, que não frequentam a escola, não concluíram a educação básica obrigatória ou não alcançaram o grau superior completo, $65,2 \%$ são negros.

Nesse seguimento, de acordo com o Censo da Educação Superior, realizado pelo Instituto Nacional de Estudos e Pesquisas Educacionais Anísio Teixeira (INEP), em 2017 havia 380.673 docentes em exercício na educação superior no Brasil dos quais a presença mais frequente era a de homens brancos com idade média de 36 anos. A racialização do espaço acadêmico, simbolizada pela frequente ausência de representação negra não é, portanto, mera coincidência, mas um projeto estatal de embranquecimento e do colonialismo epistemológico nas instituições educacionais brasileiras.

Mesmo após a abolição da escravatura no Brasil, "estudantes foram segregados em salas de aula diferentes conforme sua capacidade intelectual medida pelos testes-padrão de QI com vieses raciais" (HERNÁNDEZ, 2017, p. 64) importados dos Estados Unidos. Além disso, estudantes negros eram frequentemente afastados da escola sob o pretexto de não haverem se adaptado à vida escolar devido ao seu estado de saúde, que incluía descuido com a higiene pessoal, anemia, indiferença à educação e comportamento antissocial. 
Aqueles que persistiam e conseguiam concluir a educação básica encontravam mais obstáculos ao tentar seguir a carreira docente. Segundo Hernández (2017), para se tornar professor no Brasil, no início do século XX, era necessário realizar um treinamento profissional cuja admissão incluía um curso preparatório de um ano em escola privada. No entanto, a maioria dos negros àquela época não tinha condições financeiras para arcar com os custos e, mesmo aqueles que possuíam condições financeiras, eram submetidos a testes psicológicos para comprovar sua aptidão intelectual.

Para Fanon (2008), não basta educar o negro, mas levá-lo a não ser mais escravo de seus arquétipos. Por isso, outro problema associado à representação negra na educação diz respeito ao conteúdo acadêmico. Uma grande mudança ocorreu na literatura brasileira no final do século XX: "os personagens representados negros foram ilustrados sem aspecto caricatural na maioria das vezes. Possuem nomes próprios, contexto familiar, não estão associados à representação estereotipada de animais (...)" (SILVA, 2011, p. 33), o que simbolizou um avanço.

Esse avanço se deu em virtude de iniciativas sociais e políticas de ação afirmativa lideradas por movimentos sociais, intelectuais e pesquisadores negros e negras. Nesse quesito, "o Brasil se destaca como a nação latino-americana com o maior número de políticas de ações afirmativas voltadas para afrodescendentes" (HERNÁNDEZ, 2017, p. 139). Contudo, há uma forte rejeição à essas ações por parte da população, com base na premissa de que tais políticas são responsáveis por ampliar a segregação racial como supostamente ocorre em outros países das Américas, a exemplo dos Estados Unidos.

A justificativa utilizada é a de que não há mais obstáculos que posicionem negros e brancos em pontos de partida diferentes e, por isso, as políticas devem ser meritocráticas, isto é, baseadas nos méritos pessoais de cada indivíduo. Ocorre que, como podemos observar nos dados apresentados até o momento, sobre as discrepâncias na educação de brancos e negros, "we don't live in a meritocracy, and to pretend that simple hard work will elevate all to success is an exercise in wilful

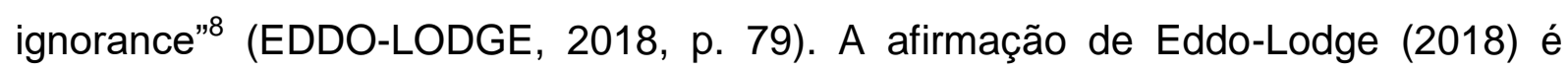
corroborada por autores como Fanon (2008) e Nascimento (1984). Mesmo quando o

\footnotetext{
8 "nós não vivemos em uma meritocracia, e fingir que o simples trabalho duro elevará todos ao sucesso é um exercício de ignorância intencional" Tradução livre.
} 
negro se destaca, com base em seus próprios méritos, suas conquistas são postas em dúvida e descrédito.

Nas Relações Internacionais não foi diferente. Os trabalhos de pensadores negros não só eram ignorados nas universidades como pesquisadores negros eram frequentemente excluídos dos quadros de professores. De acordo com Vitalis (2015), um desses casos é o de Merze Tate, a primeira mulher negra estadunidense a obter um doutorado em Relações Internacionais, em 1941, e que foi convidada a integrar o departamento de História após a oposição à sua contratação no departamento de Ciência Política. Aparentemente, a Ciência Política não era o espaço ideal para um negro, ainda mais se esse negro fosse uma mulher.

No Brasil, a situação das RI não era muito distinta. Estudos sobre questões internacionais no Brasil se deram, inicialmente, nas áreas do Direito, da Economia e da Ciência Política, e em instituições como o Itamaraty e as Forças Armadas; espaços historicamente ocupados predominantemente por homens brancos. Mas o que consolidou as $\mathrm{RI}$ como campo independente de pesquisa foi a criação do Instituto Brasileiro de Relações Internacionais (IRBI). Aberto em 1950, no Rio de Janeiro, o IRBI foi idealizado 24 anos antes do primeiro curso de graduação em RI do Brasil, fundado na Universidade de Brasília (UnB) (MEDEIROS et al., 2016).

Dessa forma, pensar as relações internacionais no Brasil estava associado, inicialmente, a instituições que não as universidades. Além disso, esse pensar era guiado muito mais por preocupações políticas, prescritivas e práticas do que por questões teóricas e de cunho reflexivo. Essas últimas, por sua vez - e por muito tempo -, se fizeram majoritariamente presentes em outras disciplinas e campos de atuação, e em análises interdisciplinares (MEDEIROS et al., 2016). Mesmo quando as $\mathrm{RI}$ passam a ganhar mais espaço na Academia brasileira, suas políticas, abordagens e metodologias se mostram arraigadas no colonialismo epistemológico (FANON, 2008) e no racismo/sexismo epistêmico (GROSFOGUEL, 2016).

O conhecimento produzido a partir das experiências sócio-históricas e concepções de mundo do Sul global - também conhecido como mundo "não ocidental" - é considerado inferior e é segregado na forma de "apartheid epistêmico" (Rabaka, 2010) do cânone de pensamento das disciplinas das universidades ocidentalizadas. Mais ainda: 0 conhecimento produzido por mulheres (ocidentais ou não ocidentais) é também visto como inferior e fora do elenco do cânone do pensamento. 
As estruturas fundacionais do conhecimento das universidades ocidentalizadas são epistemicamente racistas e sexistas ao mesmo tempo (GROSFOGUEL, 2016, p. 28).

Nesse contexto, em 2016, estudantes do departamento de Relações Internacionais da UnB - o primeiro curso de RI do Brasil -, criaram uma página nas redes sociais para divulgar e denunciar diversos casos de racismo e sexismo, entre outras práticas discriminatórias e criminosas dentro do departamento, por parte de professores e gestores. Segundo os estudantes, a página foi nomeada "No 'Melhor da América Latina" como uma maneira de ironizar a forma como foi intitulado o curso pelos docentes. Uma assembleia geral de estudantes também chegou a ser convocada e contou com a participação de mais de 200 graduandos para discutir os relatos de racismo no departamento (RODRIGUES, 2016).

Essas estruturas racistas e sexistas se tornaram consensuais e naturalizadas nos espaços de produção do conhecimento. Não há uma comoção, por exemplo, em torno do fato de que praticamente todo o conhecimento basilar das ciências sociais e humanas, discutido nas universidades contemporâneas, tenha sido "produzido por uns poucos homens de cinco países da Europa Ocidental (Itália, França, Inglaterra, Alemanha e os Estados Unidos)" (GROSFOGUEL, 2016, p. 26). De acordo com Grosfoguel (2016, p. 27), "como é que no século XXI, com tanta diversidade epistêmica existente no mundo, estejamos ancorados em estruturas epistêmicas tão provincianas camufladas de universais?".

Ainda que o estudo das RI nas Américas tenha sido fundado também a partir das relações raciais, como citado na segunda seção deste artigo, o que se observou ao longo dos anos - principalmente após a Guerra Fria - foi um distanciamento/silenciamento cada vez maior das RI em relação a essa questão, especialmente no que tange à produção acadêmica. Segundo Anievas, Manchanda e Shilliam (2015, p. 2),

(...) a search of paper titles presented at the annual meetings of the International Studies Association (ISA) shows that the words 'race', 'racism', 'racialised' and 'racist' appear in only 0.37 per cent of these titles (80 of 21,688 titles). Further, a search for the same words in article titles appearing in ISA's premier journal, International Studies Quarterly, between January 2000 and December 2007 reveal a finding of 0 per cent ( 0 of 260 titles). Indeed, one might presently speak of IR's 'racial 
aphasia'- a 'calculated forgetting' obstructing 'discourse, language and speech' (Krishna 2001; Thompson 2013). ${ }^{9}$

Para além das abordagens políticas, prescritivas e práticas que guiaram os estudos iniciais das RI no Brasil, "a discipline of IR should (...) also elaborate the significance of societal multiplicity for the social world as a whole"10 (ROSENBERG, 2016, p. 13). Para isso, é preciso repensar o internacional, e compreender que esse espaço não é produto de uma única fonte (ocidental), mas de múltiplas. E suas relações, práticas, teorias e ideologias envolvem forças coloniais, neocoloniais, racistas e sexistas que subjugam o Outro em sua identidade (PERSAUD e SAJED, 2018).

Autocrítica é, portanto, essencial para pensar as relações internacionais a partir de suas subjetividades e, consequentemente, torná-las mais transdisciplinares e democráticas. "The need for a sound empirical dimension in a working research program cannot be denied"11 (LAPID, 1996, p. 9), por isso, a realização de uma pesquisa empírica apresentará resultados valiosos para a compreensão da representação negra na produção acadêmica brasileira das RI. Dessa forma, o presente trabalho se dedicará a analisar a produção acadêmica do Banco de Teses e Dissertações do Instituto de Pesquisa em Relações Internacionais (IPRI), uma das principais plataformas dessa natureza no Brasil.

Como dispõe a apresentação da plataforma, o Banco de Teses e Dissertações do IPRI é uma lista de teses de doutorado e dissertações de mestrado defendidas no Brasil em Relações Internacionais e em áreas correlatas, com vistas a fomentar a pesquisa bibliográfica. Foi construído a partir da unificação das listas de órgãos públicos (CAPES, IBICT) e instituições de ensino superior (públicas e

\footnotetext{
9 “(...) uma pesquisa de títulos de artigos apresentados nas reuniões anuais da Associação de Estudos Internacionais (AEI) mostra que as palavras 'raça', 'racismo', 'racializada' e 'racista' aparecem em apenas 0,37 por cento desses títulos (80 de 21.688 títulos). Além disso, uma busca pelas mesmas palavras nos títulos dos artigos que aparecem na principal revista da AEI, International Studies Quarterly, entre janeiro de 2000 e dezembro de 2007, revela uma descoberta de $0 \%$ (o de 260 títulos). De fato, pode-se falar atualmente da 'afasia racial' da RI - um 'esquecimento calculado' que obstrui 'o discurso, a linguagem e a fala' (Krishna 2001; Thompson 2010)." Tradução livre.

10 "Uma disciplina de RI deve elaborar o significado da multiplicidade social para o mundo social como um todo" Tradução livre.

11 "A necessidade de uma dimensão empírica sólida em um programa de pesquisa em progresso não pode ser negada" Tradução livre.
} 
privadas) com linhas de pesquisa em Relações Internacionais e áreas afins (História, Ciência Política, Economia, Sociologia, Administração e Antropologia, entre outras).

O levantamento das teses e dissertações foi realizado entre os dias 19 e 21 de julho de 2019. Dos 4.093 trabalhos cadastrados na plataforma do IPRI, foram encontrados 37 resultados com a palavra "negro", dos quais 16 foram descartados pois faziam referência ao sobrenome Montenegro, ao Rio Negro (no Amazonas), ao elemento químico ouro, foram duplicados ou haviam sido publicados antes do Século XXI. Por fim, 21 trabalhos foram analisados.

Dos trabalhos em análise, 8 faziam parte de programas de mestrado e doutorado em História, 4 do Programa de Estudos Comparados sobre as Américas (Ceppac), 2 em Ciência Política, 2 do programa de Diplomacia do Instituto Rio Branco (IRBr), e 1 em Sociologia, Antropologia e Ciências Criminais cada. Todos esses trabalhos, em seus respectivos campos de estudo, trazem uma abordagem histórica, social e/ou simbólica da identidade e representação negra, dentro e fora do Brasil, ou em perspectiva comparada.

A representação é um conceito que, de modo geral, está intimamente ligado à identidade e ao conhecimento. Isto porque, a representação é responsável por conectar o significado e a linguagem de membros pertencentes à mesma cultura ou a culturas diferentes. Ou seja, é uma parte essencial do processo pelo qual se produz e se compartilha identidades e conhecimentos. O significado e a linguagem são, portanto, estruturantes no processo de representação, uma vez que é a partir deles que se identifica e se reconhece o Outro (HALL, 1997). "Representação tem uma dupla função: figuração e significação (...) A representação cria realidades e as próprias condições de sua existência" (DOSSIN, 2018, p. 362).

Diante do exposto, a abordagem (ou representação) histórica constitui importante ferramenta para se pensar a representação, pois se propõe a refletir sobre a condição do negro no curso da história e de que forma se inseriu no tempo e no espaço, em África e em diáspora. Isso porque, a História é um dos principais meios pelos quais se é possível refletir, discutir sobre e desconstruir estereótipos, preconceitos, julgamentos e juízos racializados. "Não é por acaso que os trabalhos com ênfase na desconstrução, nas áreas das Ciências Sociais ou das Artes, acabam por manejar um grande arcabouço histórico" (DOSSIN, 2018, p. 365). 
Nessa perspectiva, as questões raciais no Brasil se converteram, ao longo da história, em um laboratório para outros países, "pois era considerado bem-sucedido se comparado ao que ocorria nos Estados Unidos e na África do Sul. Entretanto, o Brasil desenvolveu formas próprias de manutenção da ordem racial" (DOSSIN, 2018, p. 358) em suas instituições, o que particularizou a história e a cultura brasileira, e, principalmente, a história e a cultura afro-brasileira. Dessa forma, de acordo com Dossin $(2018$, p. 365$)$ a representação histórica possui grande importância,

Uma vez que o regime de representação racializado, produtor de estereótipos, age justamente em direção à essencialização, a desconstrução parece ser o caminho mais adequado para enfrentar essas representações enviesadas, pois pode desvelar os meios pelos quais foram construídas e apontar possibilidades de ressignificação a partir de novas montagens.

Por outro lado, a abordagem social possibilita a reflexão sobre como o negro tem se inserido - ou tentado se inserir - na sociedade, por meio das políticas de ações afirmativas e a partir do seu ingresso em espaços acadêmicos e institucionais. Segundo Silva (2011, p. 25), "os estudos de representação social não são antigos. Tiveram início quando Moscovici criou o termo, escrevendo a sua obra La Psychanalise, son image e son public, em 1961".

Apesar de alguns de seus maiores expoentes serem europeus, a exemplo de Serge Moscovici (França) e Denise Jodelet (França), estudos sobre a representação social têm atraído cada vez mais a atenção dos movimentos acadêmicos brasileiros. O interesse brasileiro acerca dos estudos sobre representação social tampouco é antigo e se consolidou nos anos 90, a partir da formação de um grupo de trabalho sobre a temática nos Simpósios de Pesquisa e Intercâmbio Científico da Associação Nacional de Pesquisa e Pós-Graduação em Psicologia (ANPEPP) (SILVA, 2011).

De acordo com Silva (2011, p. 26), "compreender o conceito de representação social, (...) bem como "por que" ela é produzida, é importante para a interpretação das transformações da representação social do negro, bem como dos determinantes dessa transformação". Isso porque, a representação social do negro tende a estar associada a estereótipos, a preconceitos, a julgamentos e a juízos que 
passam a habitar a consciência desses indivíduos e a integrar o seu universo interior (SILVA, 2011).

(...) os objetos que são colocados na nossa consciência pela ideologia do recalque das diferenças, ao articularem-se com a percepção inicial do negro, transformam-no em um ser estigmatizado, na maioria das vezes, tornando-o cada vez mais estranho e não familiar. O mesmo ocorre com a representação social dos loucos, como Jodelet (1989) identificou na sua pesquisa sobre a forma como a representação construída dos loucos os afastava da comunidade na qual deveriam ser integrados (SILVA, 2011, p. 29).

No entanto, a tentativa de inserção do negro na sociedade não significa que este está, de fato, inserido, isto é, representado. A esse complexo contexto se denomina representação simbólica. Basta olhar para as universidades brasileiras, especialmente para os e as docentes, que nos deparamos com uma realidade muito distinta dos dados nacionais apresentados sobre a população brasileira. Isso se deve ao que viemos tratando ao longo do artigo, e ao que Arboleya, Ciello e Meucci (2015) definem como as discrepâncias sociais entre brancos e negros, as barreiras ao acesso a políticas públicas, bem como os tipos de oportunidades acessadas por aqueles que ascendem num mundo branco.

"Esse modelo social excludente ainda aparece claramente em engenharias institucionais e padrões de representação social do negro - o material e o simbólico articulados na negação discursiva e na prática reiterada do racismo institucional" (ARBOLEYA, CIELLO e MEUCCI, 2015, p. 885). Nesse sentido, para Petruccelli (2013, p. 17), a própria configuração de raça também constitui

(...) uma representação simbólica de identidades produzidas desde referentes físicos e culturais. Na utilização desta categoria de análise, não se trata do grupo social cujo fundamento seria biológico, mas de grupo social reconhecido por marcas inscritas no corpo dos indivíduos (cor da pele, tipo de cabelo, estatura, forma do crânio etc.).

Dito isto, entre os títulos, resumos e palavras-chave dos programas de Relações Internacionais, analisados na plataforma do IPRI, foram encontrados apenas 2 trabalhos com referências à palavra "negro". Uma dissertação de mestrado 
da Universidade de Brasília (UnB), publicada em 2012, e outra da Pontifícia Universidade Católica de São Paulo (PUC-SP), em 2001.

A primeira, defendida no Programa de Pós-Graduação em Relações Internacionais da UnB, tem o objetivo de sistematizar os elementos que possibilitam o entendimento do fim da escravização africana no Brasil, e, em um de seus capítulos, se propõe a compreender como os poderes exercidos pelo Exército e pelos próprios negros possibilitaram uma mudança de regimes, a partir da assinatura da Lei Áurea. Aqui podemos observar a utilização tanto de abordagem histórica como social, a fim de analisar a participação negra no processo de abolição da escravatura no Brasil.

Não foi possível analisar a segunda dissertação - defendida no Programa de Pós-Graduação em Relações Internacionais da PUC-SP, em 2001 - com profundidade, em razão de o link não estar disponível para acesso. Consequentemente, não conseguimos recuperar o objetivo da pesquisa, que possui "narcotráfico, drogas e política" como palavras-chave. Todavia, o que conseguimos extrair do resumo é uma crítica às leis antidrogas nas Américas, que operam como estratégia governamental para a identificação, perseguição e reclusão de pessoas dissonantes às ordens social e moral estabelecidas, a exemplo dos negros. A pesquisa apresenta, portanto, uma crítica, à representação simbólica do negro nas esferas de poder e combate às drogas.

A análise de 21 produções acadêmicas stricto sensu com menção à palavra "negro" em seus títulos, resumos ou palavras-chave, numa dimensão de 4.093 trabalhos cadastrados na plataforma do IPRI, levanta algumas dúvidas sobre a importância da linguagem na construção do pensamento e das teorias brasileiras, e sobre a representação do negro. Será, essa lacuna, decorrente da pretensão de se afastar da carga pejorativa que a palavra "negro" um dia carregou, quiçá ainda carrega? Ou, a produção acadêmica brasileira das $\mathrm{RI}$, no século $\mathrm{XXI}$, ainda é fortemente influenciada pelo colonialismo epistemológico? Ou, ainda, há outras variáveis a se considerar sobre essa representação?

Nesse sentido, o presente trabalho, ao propor uma análise empírica com base nas teses e dissertações depositadas na plataforma do IPRI, não tem a pretensão de considerar que a insipiente produção acadêmica das Relações Internacionais utilizando o marcador "negro" seja, por si só, indicativa da sub-representação da 
população negra nesse campo. Mas, é de se considerar que os dados levantados e analisados constituem um indicativo de como a produção acadêmica das RI têm abordado as relações raciais no Brasil, especialmente considerando todo o histórico de colonização, escravização e políticas públicas eugenistas no país.

\section{Considerações Finais}

A predisposição a esquecer - ou a considerar irrelevantes - as atrocidades cometidas no passado (a conquista territorial, a escravidão, a colonização, o genocídio etc.), a invisibilização do Outro em suas subjetividades, e o papel da linguagem na construção da identidade são fatores determinantes para que o colonialismo epistemológico exerça brilhantemente, ainda no século XXI, o papel de subjugar e embranquecer os saberes não-ocidentais. Consequentemente, os saberes africanos e afrodescendentes.

Em vista disso, pensar o espaço social e simbólico do negro na produção acadêmica stricto sensu das Relações Internacionais (RI) brasileiras, ainda se mostra um desafio, que demanda uma mudança no conjunto de mecanismos teóricos e metodológicos das $\mathrm{Rl}$, e das ciências, de modo geral, e o esforço e dedicação dos pesquisadores que se propõem a investigar a internacionalização de conceitos e práticas raciais no Brasil, especialmente, a partir de autoras e autores negros.

As teorias das RI não são neutras e sempre se direcionam a um ou outro grupo, afinal, teorias são lentes pelas quais vemos o mundo. No entanto, as RI precisam adotar novas lentes, pensar outras ferramentas e teorias, e se questionar sobre os limites entre teoria e conhecimento, sobre a lógica do ser no cenário internacional, e, principalmente, sobre qual é a relação entre sujeito de pesquisa e objeto de pesquisa. Se todo ser é um ser pensante e capaz de produzir conhecimento, por que há um silenciamento das RI acerca da contribuição e da representação do negro em seu campo de pesquisa?

É essencial e urgente que essas questões sejam discutidas, especialmente considerando que "(...) mainstream IR also provides prominent critiques of racism. Ignoring these critiques would misrepresent the degree of racism in the field and 
disregard the challenge to racist discourse within IR by IR theorists, themselves" ${ }^{12}$ (HENDERSON, 2015, p. 27). É nosso compromisso - enquanto pesquisadores e enquanto sociedade - decompor o que, um dia, foi aceito como verdade única e universal. É nossa missão mudar narrativas e estruturas que, ainda hoje, nos oprimem.

\section{Referências Bibliográficas}

ANIEVAS, Alexander; MANCHANDA, Nivi e SHILLIAM, Robbie (eds.). Race and Racism in International Relations: Confronting the Colour Global Line. Londres e Nova York: Routledge, 2015.

ARBOLEYA, Arilda; CIELLO, Fernando e MEUCCI, Simone. "Educação para uma vida melhor": trajetórias sociais de docentes negros. Cadernos de Pesquisa, São Paulo, v. 45, n. 158, p. 882-914, dez. 2015. Disponível em: < http://www.scielo.br/scielo.php?script=sci_arttext\&pid=S0100-

$15742015000400882 \&$ Ing=en\&tIng=en>. Acessado em 08 de fevereiro de 2020.

BENTO, Maria Aparecida Silva. Branqueamento e Branquitude no Brasil. In: Psicologia social do racismo - estudos sobre branquitude e branqueamento no Brasil. Iray Carone, Maria Aparecida Silva Bento (orgs.). Petrópolis: Vozes, 2002, p. 25-58.

BLANEY, David L.; TICKNER, Arlene B. International Relations in the Prison of Colonial Modernity. International Relations, vol.31, n.1, p. 71-75, 2017.

BRAGA, Pablo de Rezende Saturnino; MILANI, Carlos R. S. Direitos humanos e política externa no Brasil e na África do Sul: o mito da democracia racial, o apartheid e as narrativas da redemocratização. Revista Brasileira de Ciência Política, Brasília, n.29, p. 7-44, agosto 2019. Disponível em: < http://www.scielo.br/scielo.php?script=sci arttext\&pid=S0103-33522019000200007>. Acessado em 19 de dezembro de 2019.

BURKE, Anthony et al. Planet Politics: A manifesto from the end of IR. Millenium: Journal of International Studies, p. 1-25, 2016.

CARDOSO, Lourenço. Lourenço Cardoso: "Temos potencial para abolir o racismo e todas as outras formas de opressão". [Entrevista concedida a] Joana Oliveira. EL PAÍS, São Paulo, 30 de novembro de 2019. Disponível em: < https://brasil.elpais.com/brasil/2019-11-30/lourenco-cardosotemos-potencial-para-

\footnotetext{
12 "As [teorias das] RI convencionais também fornecem críticas importantes ao racismo. Ignorar essas críticas seria deturpar o grau de racismo no campo e desconsiderar o desafio ao discurso racista dentro das RI, pelos próprios teóricos das RI" Tradução livre.
} 
abolir-o-racismo-e-todas-as-outras-formas-de-opressao.html>. Acessado em 08 de fevereiro de 2020.

DOSSIN, Francielly Rocha. Sobre o regime de visualidade racializado e a violência da imageria racista: notas para os estudos da imagem. Anos 90, Porto Alegre, v. 25, n. 48, p. 351-377, dez. 2018. Disponível em: < https://seer.ufrgs.br/anos90/article/view/77582/51372>. Acessado em 08 de fevereiro de 2020.

EDDO-LODGE, Reni. Why I'm No Longer Talking To White People About Race. London: Bloomsbury Publishing Plc, 2018.

FANON, Frantz. Pele negra, máscaras brancas. Tradução de Renato da Silveira. Salvador: EDUFBA, 2008.

FUNAG. Cursos de Relações Internacionais. Disponível em: <http://www.funag.gov.br/ipri/index.php/cursos-de-relacoes-internacionais>.

Acessado em 19 de julho de 2019.

GROSFOGUEL, Ramón. A estrutura do conhecimento nas universidades ocidentalizadas: racismo/sexismo epistêmico e os quatro genocídios/epistemicídios do longo século XVI. Revista Sociedade e Estado, Brasília, vol.31, n.1, jan-abril 2016, p. 25-49.

HALL, Stuart. Representation: Cultural Representations and Signifying Practices. London: SAGE Publications, 1997.

HENDERSON, Errol A. Hidden in Plain Sight: Racism in International Relations Theory. In: ANIEVAS, Alexander; MANCHANDA, Nivi e SHILLIAM, Robbie (eds.). Race and Racism in International Relations: Confronting the Colour Global Line. Londres e Nova York: Routledge, p. 19-43, 2015.

HERNÁNDEZ, Tanya Katerí. Subordinação racial no Brasil e na América latina: o papel do Estado, o Direito Costumeiro e a Nova Resposta dos Direitos Civis. Tradução de Arivaldo Santos de Souza e Luciana Carvalho Fonseca. Salvador: EDUFBA, 2017.

IBGE. Pesquisa Nacional por Amostra de Domicílios Contínua: Educação 2018. Rio de Janeiro: Instituto Brasileiro de Geografia e Estatística (IBGE), 2019. Disponível em: <https://biblioteca.ibge.gov.br/visualizacao/livros/liv101657_informativo.pdf>. Acessado em 19 de julho de 2019.

INAYATULLAH, Naeem; BLANEY, David. International Relations and the Problem of Difference. Nova York: Routledge, 2004.

INEP. Dados do Censo da Educação Superior: As universidades brasileiras representam $8 \%$ da rede, mas concentram $53 \%$ das matrículas. Censo da Educação Superior, 03 de outubro de 2018. Disponível em: <http://portal.inep.gov.br/artigo/lasset_publisher/B4AQV9zFY7Bv/content/dados-do-censo-da-educacao-superior-asuniversidades-brasileiras-representam-8-da-rede-mas-concentram-53-das-

matriculas/21206>. Acessado em 19 de julho de 2019. 
KILOMBA, Grada. Plantation Memories: Episodes of Everyday Memories. Munster: UNRAST-Verlag, 2010.

LAPID, Yosef. Culture's Ship: Returns and Departures in International Relations Theory. In: LAPID, Yosef e KRATOCHWIL, Friedrich (eds.). The Return of Culture and Identity in IR Theory. Boulder: Lynne Rienner Publishers, p. 3-20, 1996.

MEDEIROS, Marcelo de Almeida et al. What does the field of International Relations look like in South America? Revista Brasileira de Política Internacional, 59(1): e004, 2016. Disponível em: <http://www.scielo.br/pdf/rbpi/v59n1/0034-7329-rbpi-59-0100004.pdf> Acessado em 19 de julho de 2019.

MINAYO, Maria Cecília de Souza. 2012. Análise qualitativa: teoria, passos e fidedignidade. Ciência \& Saúde Coletiva. vol.17, n.3, p. 621-626. Disponível em: < http://www.scielo.br/scielo.php?script=sci_arttext\&pid=S1413-

$81232012000300007 \& \operatorname{lng}=e n \& n r m=i s o \& t \mid n g=p t>$. Acessado em 10 de setembro de 2019.

NASCIMENTO, Abdias do. Jornada Negro-Libertária. Rio de Janeiro: IPEAFRO, 1984.

ONU. Década Internacional de Afrodescendentes. Tradução de Júlia Lins Franciotti. 2016. Disponível em: <https://nacoesunidas.org/wpcontent/uploads/2016/05/WEB_BookletDecadaAfro_portugues.pdf>. Acessado em 19 de julho de 2019.

ONU. Resolution adopted by the General Assembly on 23 December 2013. New York: United Nations, 2014. Disponível em: <https://www.un.org/en/ga/search/view_doc.asp?symbol=A/RES/68/237>. Acessado em 19 de julho de 2019.

PERSAUD, Randolph B. The Racial Dynamics in International Relations: Some Thoughts on the Pan-African Antecedents of Bandung. In: PHAM, Quyn N. and SHILLIAM, Robbie (eds.). Meanings of Bandung: Postcolonial Orders and Decolonial Visions. London: Rowman \& Littlefield International Ltd., p. 133-142, 2016.

PERSAUD, Randolph B.; SAJED, Alina. Race, Gender and Culture in International Relations. In: PERSAUD, Randolph B. e SAJED, Alina (eds.). Race, Gender, and Culture in International Relations: Postcolonial Perspectives. Londres e Nova York: Routledge, p. 1-18, 2018.

PETRUCCELLI, José Luis. Autoidentificação, identidade étnico-racial e heteroclassificação. In: PETRUCCELLI, José Luis. e SABOIA, Ana Lucia (eds.). Características Étnico-Raciais da População: Classificação e ldentidades. Rio de Janeiro: Instituto Brasileiro de Geografia e Estatística (IBGE), p. 31-50, 2013. Disponível em: <https://biblioteca.ibge.gov.br/visualizacao/livros/liv63405.pdf>. Acessado em 20 de julho de 2019.

RODRIGUES, Matheus. Estudantes da UnB criam página para denunciar preconceito de professores. G1, Distrito Federal, 04 de junho de 2016. Disponível em: $\quad<$ http://g1.globo.com/distrito-federal/noticia/2016/06/estudantes-da-unb-criam- 
pagina-para-denunciar-preconceito-de-professores.html>. Acessado em 08 de fevereiro de 2020.

ROSENBERG, Justin. International Relations in the Prison of Political Science. International Relations, vol.31, n.2, p. 1-27, 2016.

SANTOS, Milton. Por uma outra globalização: do pensamento único à consciência universal. 9 ed. Rio de Janeiro: Record, 2002.

SHILLIAM, Robbie. Non-Western Thought and International Relations. In: SHILLIAM, Robbie (ed.). International Relations and Non-Western Thought. Imperialism, Colonialism and Investigations of Global Modernity. Londres e Nova York: Routledge, p. 1-11, 2011.

Significado de Negro. Dicionário do Aurélio Online, 2019. Disponível em: <https://dicionariodoaurelio.com/negro>. Acessado em 20 de julho de 2019.

SILVEIRA, Daniel. Em sete anos, aumenta em $32 \%$ a população que se declara preta no Brasil. G1, Rio de Janeiro, 22 de maio de 2019. Disponível em: <https://g1.globo.com/economia/noticia/2019/05/22/em-sete-anos-aumenta-em-

32percent-a-populacao-que-se-declara-preta-no-brasil.ghtml>. Acessado em 19 de julho de 2019.

SILVA, Ana Célia da. A representação social do negro no livro didático: o que mudou? Por que mudou? Salvador: EDUFBA, 2011.

THOMAS, Hugh. The Slave Trade: The History of the Atlantic Slave Trade 14401870. London: Phoenix, 2006.

VITALIS, Robert. White world order, black power politics: the birth of American international relations. New York: Cornell University Press, 2015. 